\title{
Qualitative Analysis of Effective Psychological Factors on Stress and Fear of Covid- 19 Virus During Corona Outbreak Using Grounded Theory Method (GTM)
}

\author{
Majid Barzegar \\ Department of Educational Sciences, Faculty of Educational Sciences and Psychology, University of Marvdasht, Iran \\ * Corresponding author's Email: mbarzegar55@gmail.com
}

\begin{abstract}
The purpose of this study was to qualitative analysis of effective psychological factors on stress and fear of covid-19 virus during corona outbreak using grounded theory method (GTM). The emergence of a new form of coronavirus (2019-nCoV) in China created a confusing situation that was rapidly evolving and spread dramatically to other provinces and regions of China and then to the rest of the world. The aim of this study was to qualitatively analyze the psychological factors affecting stress and fear of Covid19 virus during corona outbreak using grounded theory (GTM) method among students of Islamic Azad University, Electronic Branch. This research has been a qualitative research in terms of basic purpose, in terms of descriptive-survey method and in terms of data type. The study population was the students of Islamic Azad University, electronic unit and the selected sample was 30 students studying in the second semester of 2019-20 of this university unit who were selected by available sampling method. The tool used in the research was a semi-structured interview that was conducted online. Findings showed that 6 psychological factors affecting stress and fear of Covid-19 virus were identified as worry about virus infection, socio-economic consequences, fear of strangers, traumatic stress symptoms, emergency response and fear. from the 6 factors identified, 5 factors were located in the stress nucleus and 1 factor in the fear nucleus of Covid-19 virus. According to the identified factors, it is predicted that when we go through this epidemic, significant mental health needs will appear in people who need measurements to provide a useful solution to improve the mental health of people.
\end{abstract}

Keywords: Stress, Fear, Covid-19, Grounded Theory

\section{Introduction}

The emergence of a novel form of coronavirus (2019-nCoV), in December 2019, in Wuhan, China, created a confusing and rapidly evolving situation and quickly spread to other provinces/regions of the country and then to whole world (Shigemura et al., 2020; Wang et al., 2020). On 30 January 2020, the World Health Organization (WHO) declared this disease a 'public health emergency of international concern.' By March 29th, 213 countries/territories had confirmed cases (World Health Organization, 2020a) with an extremely high infection rate and relatively high mortality. As ever in the early stages of a major incident, facts are unclear. We unsure about how many people have caught the disease, the fatality rate, the incubation period, how far it has spread - or how worried or afraid we should be. For this reason, many countries have implemented of unprecedentedly strict quarantine measures. 'Quarantine is the separation and restriction of movement of people who have potentially been exposed to a contagious 
disease to ascertain if they become unwell, so reducing the risk of them infecting others (Centers for Disease Control and Prevention, 2017). A more recent analysis of the mortality rate in locations with early quarantine procedures suggests that the true rate to be no more than $1 \%$ (Rajgor et al. 2020). While the symptoms of COVID-19 mimic the conditions caused by other coronaviruses (e.g., coughing, fever, and fatigue; Wang et al. 2020), many infected individuals can appear asymptomatic (Holshue et al. 2020), and thus can unwittingly transmit the virus to others in their vicinity. Emerging findings from China suggest that more than $25 \%$ of the general population experienced moderate to severe levels of stressor anxiety-related symptoms in response to COVID-19 (Qiu et al., 2020; Wang et al., 2020). Studies of previous epidemics and pandemics show that anxiety, or the lack thereof, is an important driver of behavior (Taylor, 2019). People with too little anxiety about a viral outbreak are less likely to engage in hygiene behaviors (e.g., handwashing), less likely to adhere to physical distancing mandates, and are less likely to get vaccinated if a vaccine is available (Taylor, 2019). On the other hand, people with excessive anxiety are more likely to engage in socially disruptive behaviors, such as panic buying and surging unnecessarily into hospitals and clinics when they misinterpret their minor ailments as signs of serious infection (Asmundson \& Taylor, 2020a, 2020b). Research and clinical observations (e.g., Taylor, 2019) suggest that during times of pandemic many people exhibit fear and anxiety-related distress responses that include the following: Fear of becoming infected, fear of coming into contact with possibly contaminated objects or surfaces, fear of foreigners who might be carrying infection (i.e., disease related xenophobia), fear of the socio-economic consequences of the pandemic (e.g., job loss), compulsive checking and reassurance-seeking regarding possible pandemic-related threats, and traumatic stress symptoms about the pandemic (e.g., nightmares, intrusive thoughts) (Taylor, Landry, Paluszek, Fergus \& et al., 2020).

According to Ahorsu et al. (2020), one unique feature of pandemic viral infections is the fear that they can instill across large swathes of the population. Fear is a negative emotion symptomized by extreme levels of emotive avoidance in relation to specific stimuli (Perin et al. 2015; Cited by Harper, Satchell, Fido \& Latzman, 2020). It is associated with clinical phobias and social anxiety disorder (Krueger et al. 2018; Cited by Harper et al., 2020), and as such the potential for widespread public fear caused by pandemic viral infections could lead to significant levels of mental distress at the population level. This was implicated in a tweet published by Dr. David Murphy (president of the British Psychological Society) that highlighted fear and anxiety (operationalized as managing health anxiety and coping with worry about relatives) as targets for psychological input within the COVID-19 pandemic.

In Iran, the Iranian government, following the Royal Decree for a state of alarm, ordered a nationwide emergency measure to prevent spreading of the infection. There was no quarantine in the country. But as of February $14^{\text {th }}$, there were restrictions on exit of home. For example, universities and schools were closed and education was provided online. Telework was considered for employees. In this time, Iranian people self-isolate at home; although, from February $14^{\text {th }}$ according levels of outbreak, with have 
different levels of restrictions across Iran's cities. This measure has kept a large number of people in isolation and affected many aspects of their lives (Brooks et al., 2020; Qiu et al., 2020). In fact, many studies have shown the COVID-19 pandemic has caused serious threats to people's physical health and lives such as feeling anxiety and stress (Dong and Zheng, 2020; Liu, 2020; Shigemura et al., 2020; Qiu et al., 2020).

\section{Material and Methods}

The reporting of results of this study follows the Consolidated criteria for reporting qualitative (COREQ) guidelines for qualitative research (Tong, Sainsbury \& Craig, 2007; Baghirathan, Cheston, Hui, Chacon et al., 2020). Iranian people, like many Countries of the world, have been affected by the Corona virus. The aim of this study was to generate a grounded theory. The following question guided the study: What comes to your mind when it comes to the corona virus? We asked the participants this question and asked them to give us a complete honest answer.

In this study, the grounded theory method with the version of Strauss and Corbin (1990), which emphasizes the discovery of the processes behind social interactions with a systematic analysis, was used as a suitable method for the study. The research population included students of the Azad University of the electronic unit. In this study, 30 people formed the research samples. First, 15 students (male and female) were interviewed using purposive sampling. Then, based on the data obtained from the research, classes, specific characteristics that appeared in each class and the need for saturation within the classes, theoretical sampling of 15 other cases was performed. The online interview method was also used to complete the data. The researcher found the desired samples and after obtaining the necessary agreement to conduct the interview and participate in the study, he conducted the interview. The main method for data collection in this study was Semi-Structured In-depth Individual Interview. Due to the online nature of the interview, the level of tolerance, information and willingness of the participants; All interviews were conducted in one session. The interviews were conducted using audio recordings and immediately after the interview, they were transcribed verbatim. The original interview was conducted in a secure location, with initial analysis and coding of each interview data prior to the next interview.

In total, 900 minutes of interviews were conducted and analyzed in detail. The use of continuous comparison techniques between data, emerging classes, and assumptions derived from field notes and notes guided the researcher to continue the theoretical sampling process until data saturation in each class.

Analysis method in this research was the open, axial and selective three-step coding method of Strauss and Corbin as a basic approach with a modified operational model of Eaves (2001) which is a combined model with the basis of Strauss and Corbin analysis (Eaves, 2001) to The title of the practical framework for conducting analysis has been used. Of course, in this study, some parts, such as causal and interventional conditions, were modified by the researcher and came under the title of conditions under 
the classes. To ensure the validity and reliability of the study, validation, or data strength, was used, which was intended to emphasize the writing of multiple reminders, theoretical sampling, accuracy in coding and classification. Emphasis was also placed on comparisons between and between data to enhance accuracy. For (Diversity) and Accuracy, the level of accuracy that the ability to generalize the created theory to the context of the study is more appropriate, theoretical sampling with maximum diversity was performed, which is evidenced by the diversity of study samples (Jeon, 2004). The researcher carefully selected key informants, combining data collection methods such as in-depth interviews, field notes, and note-taking to try to ensure data validity.

Also, from continuous review, simultaneous analysis of data and continuous comparison of data and classes in terms of similarities and differences, allocating enough time to conduct interviews and following up on disputes regarding the clarification of codes by e-mail and reviewing observers in access Real data was used. External monitoring was also a way to assess homogeneity; That is, we gave the data to a researcher who had nothing to do with the research to see if he or she had a similar understanding of the data. Does he draw the same conclusion from this data? When the research reports, manuscripts and notes were given to another researcher, similar findings were extracted and the disputed items were reviewed more closely to ensure that the data were determined objectively. To provide Fitness and transferability of generalizing the results to other groups and similar environments; The results of the research were made available to a number of students and professors in the field and faculty members who were not participants in the present study, to examine its transferability and appropriateness. The result of this process, while confirming the findings, was the presentation of a series of complementary experiences and perspectives that were used in the data analysis process.

The review of the observers included the use of complementary opinions of colleagues, review of manuscripts by participants, professors and colleagues familiar with qualitative research. By practicing the sense of responsiveness, creativity and sensitivity of the researcher in the research process, an attempt has been made to observe the criteria of researcher acceptance as an essential component in qualitative research.

\section{Results}

The results of demographic characteristics of the participants in the study showed that out of 30 participants, 21 (male) and 9 (female). Participants ranged in age from 25-45 and were mostly married (24 people). In terms of education level, 26 people had a master's degree and 4 people had a bachelor's degree. Regarding employment, $17 \%$ of health care workers, $34 \%$ bank employees, $25 \%$ education employees and $18 \%$ self-employed. $6 \%$ were only students and did not have any job. 
Qualitative Analysis of Effective Psychological Factors on Stress and Fear of Covid-19 Virus...

\section{Qualitative results (Open-source presentation)}

Table 1. Coding of stress and fear variables of Covid-19 virus

\begin{tabular}{|c|c|c|}
\hline Core code & Axial coding & Open coding \\
\hline \multirow{33}{*}{$\begin{array}{l}\text { Stress of COVID- } \\
19\end{array}$} & \multirow[t]{12}{*}{ Worried infected to Virous } & infecting with the virus \\
\hline & & Inability to protect the family against the virus \\
\hline & & $\begin{array}{l}\text { The inability of healthcare to protect loved ones and families against } \\
\text { the virus }\end{array}$ \\
\hline & & The inability of healthcare to protect me against the virus \\
\hline & & Insufficient hand washing \\
\hline & & Insufficient social distance \\
\hline & & Touching doors and railings in public \\
\hline & & Sneezing or coughing in public \\
\hline & & infecting by through those around \\
\hline & & transfer money by hand \\
\hline & & Handling money or using an ATM or card reader \\
\hline & & Participating in celebrations and epochs \\
\hline & $\begin{array}{l}\text { Socio-economic } \\
\text { consequences }\end{array}$ & Lack of disinfectants \\
\hline & & Lack of cold Drug \\
\hline & & Lack of immune-boosting drugs \\
\hline & & Lack of masks and gloves \\
\hline & & Lack of alcohol \\
\hline & Xenophobia & Presence of strangers in restaurants \\
\hline & & Contact with strangers \\
\hline & & $\begin{array}{l}\text { Use of public environment elevators such as hospitals and } \\
\text { workplaces }\end{array}$ \\
\hline & Traumatic stress symptoms & Difficulty concentrating \\
\hline & & severe headache \\
\hline & & stomach ache \\
\hline & & Obsession in hand washing \\
\hline & & Obsession with disinfecting workplace equipment \\
\hline & & Social media news about Corona \\
\hline & & reporting increasing Mortality rates by national media \\
\hline & & reporting increasing virus infecting rates by national media \\
\hline & & reopening of schools \\
\hline & compulsive checking & Searching in internet to finding a cure \\
\hline & & Consultation with doctors and health professionals \\
\hline & & Constantly check body temperature and breathing status \\
\hline & & $\begin{array}{l}\text { Constantly check body temperature and breathing status of family } \\
\text { members }\end{array}$ \\
\hline \multirow[t]{2}{*}{ Fear of COVID-19 } & Fear & Death of relatives due to infection to Virus \\
\hline & & My own death due to infection to Virus \\
\hline
\end{tabular}




\section{Discussion}

The aim of this study was to qualitatively analyze the psychological factors affecting stress and fear of Covid-19 virus. According to the study, 6 psychological factors affecting stress and fear of Covid-19 virus were identified under the heading of worrying about being infected with the virus, socio-economic consequences, fear of strangers, traumatic stress symptoms, emergency response and fear. Of the 6 factors identified, 5 factors were located in the stress nucleus and 1 factor in the fear nucleus of Covid19 virus. These predictions are based on previous epidemics, in which anxiety, depression, and traumatic reactions have been observed (Hawryluck et al., 2004; Taylor, 2019). Accordingly, a specific measure in the area of the pandemic can help identify individuals at risk for adverse emotional reactions, both during and after the pandemic. This can help public health authorities allocate resources for mental health interventions. It can also be used to predict the return to function after an epidemic. It can be said that this is the first assessment of emotional responses related to the epidemic, which includes a specific assessment of xenophobia as a contributing factor to fear and avoidance, which is important in any preparation for public health officials in addressing emotional and behavioral responses. It is possible for epidemics. The role of xenophobic reactions, along with other emotional indicators such as those identified in the study (concern about virus infection, socioeconomic consequences, fear of aliens, traumatic stress symptoms, emergency response, and fear) requires further investigation. For example, for people at risk for post-epidemic adverse reactions. In terms of limitations, the present study did not include structured diagnostic evaluations (e.g., DSM-5 diagnoses). This study was also limited to online evaluation and online interviews.

Conflict of interest: The author stated no conflict of interest in the study.

Financial sponsor: The author acknowledged that they he not received any financial support for all stages of the study, writing and publication of the paper.

\section{References}

Ahorsu, D. K., Lin, C. Y., Imani, V., Saffari, M., Griffiths, M. D., \& Pakpour, A. H. (2020). The fear of COVID-19 scale: development and initial validation. International journal of mental health and addiction, 1-9.

Asmundson, G. J., \& Taylor, S. (2020). Coronaphobia: Fear and the 2019-nCoV outbreak. Journal of anxiety disorders, 70, 102196.

Baghirathan, S., Cheston, R., Hui, R., Chacon, A., Shears, P., \& Currie, K. (2020). A grounded theory analysis of the experiences of carers for people living with dementia from three BAME communities: Balancing the need for support against fears of being diminished. Dementia, 19(5), 1672-1691.

Brooks, S. K., Webster, R. K., Smith, L. E., Woodland, L., Wessely, S., Greenberg, N., \& Rubin, G. J. (2020). The psychological impact of quarantine and how to reduce it: rapid review of the evidence. The Lancet. 
Dong, M., \& Zheng, J. (2020). Letter to the editor: Headline stress disorder caused by Netnews during the outbreak of COVID- 19. Health Expectations: An International Journal of Public Participation in Health Care and Health Policy, 23(2), 259.

Eaves, Y. D. (2001). A synthesis technique for grounded theory data analysis. Journal of advanced nursing, 35(5), 654-663.

Harper, C. A., Satchell, L. P., Fido, D., \& Latzman, R. D. (2020). Functional fear predicts public health compliance in the COVID-19 pandemic. International journal of mental health and addiction.

Hawryluck, L., Gold, W. L., Robinson, S., Pogorski, S., Galea, S., \& Styra, R. (2004). SARS control and psychological effects of quarantine, Toronto, Canada. Emerging infectious diseases, 10(7), 1206.

Holshue, M. L., DeBolt, C., Lindquist, S., Lofy, K. H., Wiesman, J., Bruce, H., ... \& Diaz, G. (2020). First case of 2019 novel coronavirus in the United States. New England Journal of Medicine.

Jeon, Y. H. (2004). The application of grounded theory and symbolic interactionism. Scandinavian journal of caring sciences, 18(3), 249-256.

Liu, K. (2020). How I faced my coronavirus anxiety. Science, 367(6484), 1398-1398.

Qiu, J., Shen, B., Zhao, M., Wang, Z., Xie, B., \& Xu, Y. (2020). A nationwide survey of psychological distress among Chinese people in the COVID-19 epidemic: implications and policy recommendations. General psychiatry, 33(2).

Rajgor, D. D., Lee, M. H., Archuleta, S., Bagdasarian, N., \& Quek, S. C. (2020). The many estimates of the COVID-19 case fatality rate. The Lancet Infectious Diseases, 20(7), 776-777.

Shigemura, J., Ursano, R. J., Morganstein, J. C., Kurosawa, M., \& Benedek, D. M. (2020). Public responses to the novel 2019 coronavirus (2019- nCoV) in Japan: Mental health consequences and target populations. Psychiatry and clinical neurosciences, 74(4), 281.

Strauss, A., \& Corbin, J. (1990). Basics of qualitative research. Sage publications.

Taylor, S. (2019). The psychology of pandemics: Preparing for the next global outbreak of infectious disease. Cambridge Scholars Publishing.

Taylor, S., \& Asmundson, G. J. (2020). Life in a post-pandemic world: What to expect of anxiety-related conditions and their treatment. Journal of Anxiety Disorders, 72, 102231.

Taylor, S., 2019. The Psychology of pandemics: Preparing for the Next Global Outbreak of Infectious Disease. Cambridge Scholars Publishing, Newcastle upon Tyne.

Taylor, S., Landry, C., Paluszek, M., Fergus, T. A., McKay, D., \& Asmundson, G. J. (2020). Development and initial validation of the COVID Stress Scales. Journal of Anxiety Disorders, 102232.

Tong, A., Sainsbury, P., \& Craig, J. (2007). Consolidated criteria for reporting qualitative research (COREQ): a 32-item checklist for interviews and focus groups. International journal for quality in health care, 19(6), 349357.

Wang, C., Pan, R., Wan, X., Tan, Y., Xu, L., Ho, C. S., et al. (2020). Immediate psychological responses and associated factors during the initial stage of the 2019 coronavirus disease (COVID-19) epidemic among the general population in China. International Journal of Environmental Research and Public Health, 17, 1729.

World Health Organization (WHO) (2020). Coronavirus disease (COVID-19) pandemic. March 11 https://www.who.int/emergencies/diseases/novelcoronavirus2019. 